\title{
Development of Critical Thinking Skills through Writing Tasks: Challenges Facing Maritime English Students at Aqaba College, AlBalqa Applied University, Jordan
}

\author{
Ali Odeh Hammoud Alidmat ${ }^{1} \&$ Mohamed Ayed Ayassrah $^{1}$ \\ ${ }^{1}$ Lecturer-Department of Basic Sciences, AlBalqa Applied University, Jordan \\ Correspondence: Ali Odeh Hammoud Alidmat, Lecturer-Department of Basic Sciences, AlBalqa Applied University, \\ Jordan
}

Received: February 28, 2017

Accepted: May 2, 2017

Online Published: May 22, 2017

doi:10.5430/ijhe.v6n3p82

URL: https://doi.org/10.5430/ijhe.v6n3p82

\begin{abstract}
Teaching English for Special Purposes (ESP) in a context where English is taught as a Foreign Language (EFL) is no easy task. There is in fact extensive research reporting on challenges facing both teacher and student in the Foreign Language classroom where language skills must be learnt outside their usual context. Even more challenging is teaching or learning a conceptual skill like critical thinking through writing in an EFL context. The objective of this paper is to identify and describe writing tasks contained in the ESP programme with a view to examine the correspondence between the tasks and the critical thinking skills. To this end, the study examines self-reported perceptions, experiences and opinions by Maritime English students of Aqaba College in Jordan who take an ESP course and who are supposed to develop their critical thinking skills through carefully selected writing tasks in English. The study applies the qualitative procedure of in-depth interview and explores a sample of 10 finalist undergraduate informants on issues related to their writing tasks in English. Findings of the study revealed, among other things, that there is low correspondence between writing tasks contained in the ESP programme and critical thinking skills, and that writing tasks featured in the programme pursue more mechanical writing than thinking.
\end{abstract}

Keywords: Critical thinking, Writing tasks, English for Special purposes, English as a Foreign language

\section{Introduction}

Of the language skills involving listening, speaking, reading and writing, writing is the most advanced. This means that writing should be engaged in by someone who has no problem listening, speaking and reading. As in many contexts in the Middle East and elsewhere, Jordanian students learn English as a Foreign Language. At college or university level, they may also learn English for Special Purposes, usually related to the field in which they major.

English is in great demand in Jordan as it is in many non-English speaking parts of the world. It is therefore taught as a subject beginning from junior school. However, the overwhelming pressure from Arabic outside school leaves very few domains in which learners can exercise their knowledge of English. With regard to writing, the fact that the Arabic writing system itself is totally different from English does not help matters. Yet this is only as far as knowing how to write the English alphabet is concerned. Perhaps even more difficult to attain is the proficiency level expected of ESP students who are required to engage in cognitive skills of analysis, inference and evaluation in the English language. As Al-Khasawneh (2010) rightly points out, Arab learners of English still have many problems when writing in English, like not knowing how to organize their ideas, because it is a new experience for them. According to Al-Khasawneh, foreign students can only succeed with a foreign language if their language learning environment reserves some functions for the foreign language.

Students at Aqaba College take General English as a common course, so they learn it alongside their majors. However, Maritime students must take an ESP course specially designed for Maritime studies. One of the goals of the course is to develop critical thinking skills in English. Like other courses involving international contact, English is especially important to these students. There are only two maritime institutions in Jordan that produce graduates for the Maritime industry. Because of the large water bodies nearby, Jordan is one of the countries relied upon to produce qualified human resources to serve in the seafarer industry. 
As is the case with many industries with an international frontier, maritime technical jargon exists mainly in English; so, graduates who hope to serve in the field should be proficient in English communication skills. However, there is some concern that maritime professionals generally lack English communication skills (Winbow, 2002). At least in the Middle East region where Arabic is usually the official and national language. This tendency is especially attributed to the rather peripheral status of English.

Difficulties faced by Arab students who learn English as a Foreign Language is extensively reported in the literature (Abbad, 1988; Rashid and Hashim, 2008; Rabab`ah, 2003; Zughoul and Taminian, 1984). So Arab students from Jordan are no exception. Reasons for this difficulty are likewise documented. For instance, Rabab'ah traces the problems of acquiring English among Arab learners to a formal instruction by the language teachers who are themselves native speakers of Arabic, and whose knowledge of English is sometimes imperfect.

Explanations provided for poor proficiency in English among Arab learners range from learner background, teaching methods to the context outside school. In the Arab region, most students join university without a proper background in English as a subject. This is the case even for students who proceed to enroll into the English program. Maybe this explains why many students taking English still struggle with mechanics of writing involving punctuation, capitalization, spelling, sentence structure and the like. A study conducted by Rashid and Hashim (2008) with Arab students of business came to the same conclusion. Other studies place the blame on both teachers and the context of learning English. According to Abbad (1988), the problems are due to inappropriate methods of language teaching and the learning environment in which English is learnt. In Jordan, English usually has no much use outside school.

\section{Review of Related Literature}

\subsection{Writing Skills}

Unlike reading, writing improves learning in a different way; it demonstrates the fact that learning took place. In the ESP program for seafarers, students are normally exposed to listening, speaking, reading and writing skills simultaneously. This means a student with a weak foundation in the earlier three skills will have difficulty with writing. In relation to thinking, writing is a medium of expressing thought.

The productive nature of writing can be challenging if tasks are not well thought out because writing involves discovering how to find the most effective way for communicating ideas. Yet without this skill, it might be difficult or impossible for the ESP students to exercise their thinking in the target language (cf. Peyton, 1993; Tran, 1997). Learners often experiment with words, sentences, and larger chunks of writing to communicate their ideas effectively and to reinforce the grammar and vocabulary they can learn in class (Bello, 1997).

Writing is a unique skill because it is usually taught in the classroom setting. Progress with this skill is however difficult if the teacher attempts to teach how to write together with what to write. At Aqaba College, for instance, students are encouraged to summarize their lecture notes, which they readily do in Arabic but not in English. This means their usual writing behavior is in Arabic. To get them to reason, evaluate, show judgement or solve a problem by means of writing is therefore a challenge. This paper seeks to find out whether students of ESP will have acquired reasoning skills and the like in English through writing practices that they undergo by the end of their programme.

Discussions about writing usually revolve around how to write and what to write. Sometimes the former skill comes before the latter; sometimes both are developed together. Whatever the case maybe, theories of writing follow product, process and genre.

From the product perspective, the foreign language teacher lays emphasis on the form or how to write. In this approach, the student is taught mechanics of writing involving punctuation, capitalization, spelling, and sentence structure. They are also exposed to rhetorical drills (Silva, 1990). As explained by Hyland (2003) and Tribble (1996), the process approach focuses more on stages of preparing a written material than the outcome. The process theory emphasizes stages of writing like pre-writing, drafting, evaluating and revising. The genre approach expounded by Swales (1990) is more specialized. In this approach, the teacher puts makes effort in helping learners write an essay with a clear purpose. Students learn by choosing the most suitable and expressive language means for the desired output. The overall goal of this approach is to familiarize the students with the conventions of a kind of writing that is relevant to their situation.

The ESP programme for Maritime students at Aqaba College offers five courses about the English language. The students are initially offered General English which refreshes the four language skills of listening, speaking, reading and writing. Students who join university in Jordan will have learned these skills in English at an earlier level. Next is an advanced course in general English which prepares the students for the specialized stages of using English. It is after these two preparatory stages that Maritime Students are introduced to ESP 1. ESP 1 familiarizes learners with 
the use of English in the Maritime context. ESP2 which follows 1 is therefore a more advanced English course for seafarers.

Each of the ESP courses is designed in such a way that the four skills of language are presented simultaneously, i.e. the unit topics are distributed such that they cover each skill. This paper is particularly interested in units that address the components of writing in English within the ESP programme. From the programme, writing activities include descriptive essays, instructions, various reports (of weather, incidents, changes, trends etc), travel plans, safety notices, job descriptions, formal letters, reviews of weather report, directions, notes, and argumentative essays involving cause and effect.

\subsection{Critical Thinking Skills}

Many scholars have explained what critical thinking is. According to Sumner (1906) critical thinking means the examination and test of propositions of any kind which are offered for acceptance, in order to find out whether they correspond to reality or not. To Paul (1989) critical thinking is that mode of thinking - about any subject, content or program - in which a thinker improves the quality of his or her thinking by skilfully taking charge of the structures inherent in thinking and imposing intellectual standards upon them. Chane (1986) on the other hand views critical thinking as the ability to analyze facts, generate and organize ideas, defend opinions, make comparisons, draw inferences, evaluate arguments and solve problems.

Some scholars understand critical thinking within the framework of cognition. According to Delphi conceptualization (Quitadamo and Kurtz, 2007), critical thinking includes analysis, inference and evaluation. From this perspective, analysis involves breaking a concept or an idea into component pieces to understand their inherent relationships. Inference is used to reconcile what is known with what is unknown while evaluation considers available evidence with a view to arriving at reasonable conclusions. Quitadamo and Kurtz add interpretation, explanation, and self-regulation as important critical thinking skills, arguing the skill includes the tendency to seek the truth, to be open-minded, to be analytical, to be orderly and systematic, and to be inquisitive.

There are obviously more ideas in the literature about what critical thinking is than there is space and time in this paper to discuss. Critical thinking involves reasoning, evaluation, judgement and problem solving. One can consult Ennis (1985), Fisher (2001), Scardamalia and Bereiter(1987), Wade (1995) or Duron, Limback, and Waugh (2006) for a detailed explanation. This paper however focuses more on the match between writing tasks given to ESP students of Aqaba College and the skills we have characterized above as critical thinking.

\subsection{Developing Critical Skills through Writing Tasks}

Researchers who believe writing contributes to development of critical thinking understand the acquisition of writing skills as a manifestation of thinking. This is because writing itself is a medium for expressing and communicating thought (Rivard, 1994; Klein 2004). Writing improves thinking because it requires an individual to make their ideas explicit and to evaluate and choose among tools necessary for an effective discourse (Quitadamo and Kurtz, 2007).

The connection between writing and critical thinking in the school context has been elaborated by various scholars because critical thinking encompasses a broad range of skills as well as sub-skills. Bloom (1956) identified six levels of intellectual behaviour in learning which require critical thinking including knowledge, comprehension, application, analysis, synthesis, and evaluation. Wade (1995), on the other hand, operationalizes critical thinking in the context of learning into activities like asking questions, defining a problem, examining evidence, analyzing assumptions and biases, avoiding emotional reasoning, avoiding over-simplification, considering other interpretations and tolerating ambiguity.

So intertwined are writing and critical thinking skills that one is sometimes unable to separate the two. Northedge (2005) outlines key principles that characterize an academic discourse which are evident in writing but which also demonstrate critical thinking. The principles are - Debate: arguing different points of view; Scholarship: awareness of what else has been written and citing it correctly; Argument: developing points in a logical sequence which leads to a conclusion; Criticism: looking at strengths and weaknesses; Analysis: taking the argument apart; Evidence: ensuring that the argument is backed by valid data; Objectivity: the writing should be detached, and Precision: anything that does not assist the argument should be omitted.

By means of these principles, writing is an active process allowing improved thought. It provides a context for interpretation and enables higher order of thinking (Resnick, 1987; Marzano, 1991). Undergraduates are expected to master critical thinking skills during their college education, regardless of discipline (Greenlaw and DeLoach 2003). 
However, and as is rightly pointed out by Ackerman (1993), it is not the case that all writing enables critical thinking. Learners at the early stages of learning to write like ESP students of Aqaba College usually fall victim of other preoccupations with the art of writing such as spelling, punctuation, and correctness of sentence structure. Under these circumstances, the cognition ideal becomes only secondary. Survey of writing tasks available to these students also reveals inclusion of tasks in the course plan which triggers relatively low levels of thinking if any.

In the classroom, however, how much thinking can be triggered by writing depends first and foremost on the choice of writing tasks. Writing tasks like copying or writing down dictated notes do not require cognition of any sort. Higher level writing tasks demanding evaluation, inference, comparison or examination are similarly of no use to the beginning writer who still must learn how to compose ideas. The dilemma of what to present as writing tasks gets worse with ESP students whose proficiency in English remains low even as they graduate.

The importance of writing skills in development of critical thinking skills cannot be overemphasized. Students who excel in writing will have their thinking boosted as well. However, critical thinking skills are undermined when writing tasks are poorly chosen or when students are at a lower level in their writing ability than can benefit their thinking skills however carefully chosen the tasks may be.

This paper examines possible levels of critical thinking skills achieved through writing tasks offered to Maritime ESP final year students of Aqaba College, Jordan. The paper views communication, logical and independent thinking skills as important for students in preparation for their practice in the job market. The paper therefore identifies and describes specific writing tasks offered to Maritime ESP final year students of Aqaba College. Secondly, the paper establishes how ready the students are in undertaking the writing tasks in the ESP course. Finally, it interrogates kinds and levels of critical thinking skills achievable through the writing tasks.

\section{Methods}

The primary research question of this paper is to find out and examine writing tasks contained in the ESP programme and to interrogate the correspondence between the tasks and the critical thinking skills. This study used qualitative methodology because it is the ideal procedure normally used in research to collect information regarding opinions, attitudes, behaviour and experiences of the informants. An in-depth interview method was used because the researcher needed to collect detailed information about perceptions, experiences and opinions of informants who are people experiencing with a structured programme. The method was especially chosen because it allows the interviewee to speak freely thereby providing as much information as possible.

Ten (10) out of 50 Maritime students taking ESP were purposively sampled to participate in the study. The 50 students were first arranged in order of merit based on their aggregate scores in the ESP course. Next, the 50 participants were divided into 5 groups of 10 loosely rather than neatly arranged into categories of "very good", "good", "moderate", "poor", and "very poor". Two (2) students from each of the 5 groups were then selected based on their readiness to participate in the study.

Objectives of the study were addressed in three steps. The first step involved a survey of writing tasks contained in the course books used for ESP1 and ESP2. At this level, the writing tasks are identified and described. The second level of the analysis examines responses from each of the informants to the interview guideline issues discussed with them concerning their perceptions, experiences, and opinions. The third level matches writing tasks examined at the second level with the range of critical thinking skills elaborated in the introduction section of this paper.

\section{Results and Discussion}

\subsection{Writing Tasks in ESP1 and ESP2}

As is mentioned in section 1.1., ESP 1 familiarizes students with the use of English in the Maritime context. ESP 2 is an advanced stage of the course featuring more or less the same writing tasks. Each topic unit for the course is designed in such a way that it focuses on an aspect of the language that feeds writing in one way or another. Let us look at the topic units closely.

The first topic of ESP 1 is "English at Sea". The topic covers suggestions for studying at sea and strategies for coping with language learning difficulties. Key language focus areas for this unit include grammar, vocabulary, pronunciation, function and study skills. Developers of this course clearly appreciate the fact that language skills are intertwined in a complex way. Therefore, they include grammar and vocabulary so that the learner has building materials for writing. However, function and study skills component of this unit are worth elaborating because they are both strategic and fall midway between grammar - vocabulary and writing. 
The course offers "giving opinions", "agreeing" and "disagreeing" as content. As we have seen from section 1.1., the three are key components of reasoning, evaluation and judgment. The study skills focus draws the attention of the learner to practicing with ideas and vocabulary from "English at Sea". Assuming the context is built, the course unit progresses into each of the key language skills in the context of "English at Sea".

The listening skill in this unit presents learners with a recorded narrative about "English at Sea" so they can get the gist of language use in the sea domain, the vocabulary, the style, the mindset, the setting and the pronunciation. After listening, learners are invited to a session in which they can speak about what they heard, what they did not understand, their opinions about what they heard and whether they have had related experiences. Next is the unit on reading. In this unit, learners read a related magazine article about seafarer experience. The aim of the exercise is to build what there is to know about the sea; the vocabulary, the challenges and the like. Up to this point, it is assumed that the learner is ready to undertake a writing task related to the sea. The course then builds on this context during subsequent units. I will only sketch a few of these below to avoid unnecessary redundancy.

Other units in the course focus on related topics to the Sea experience like "at the crewing office", "in transit", "a safety culture" and "weather report". For each unit, the thread of skills follow through in very much the same manner as described above. Usually, the unit outline begins with a hypothetical context. Let us take "in transit" for exemplification purposes. In this unit, learners are presented with a scene where an incident occurs on board. Grammar items that are focused select clause building mechanisms that are necessary in reporting an incident like relative clauses. The grammar also covers the simple past and aspect which will be handy in relating incidences. The function task correspondingly covers a description and a report of an incident. All the other activities outlined in this unit like listening, speaking and reading address nothing else but the "incident on board". At the close of the unit, the learners are asked to write "An incident report".

ESP1 and ESP2 courses offer a variety of writing tasks strictly following the foregoing format of the unit activity. As is shown above, each of the ESP courses is designed in such a way that the four skills of the language are presented simultaneously, i.e. unit topics are distributed such a way that they cover each skill.

From the course books, writing activities include descriptive essays, instructions, various reports (of weather, incidents, changes, trends etc.), travel plans, safety notices, job descriptions, formal letters, reviews of weather report, directions, notes, and argumentative essays involving cause and effect. Learners are therefore expected to be able to carry out a writing task at the end of each course unit. The question to be asked is whether they will fulfill this expectation.

Writing is more than putting correct sentences together. It is therefore not enough that the learner knows relevant vocabulary or sentence building mechanisms. Whether the write up is about "at the crewing office", "in transit", "a safety culture" or "weather report", the learners must understand the purpose for which they are writing. What function will the writing serve? Are we writing to offer, seek or demand information? Function dimension dictates whether writing achieves its purpose or not. Yet this dimension requires more knowledge of English than ESP students usually possess if their foundation is poor in English as is the case with the subjects of this paper.

To benefit from the course, ESP teachers need to make more effort in making learners write a dissertation with a clear purpose. This specialized characteristic of writing is expounded by Swales (1990) in the genre approach. Learners must be made to learn by choosing the most suitable and expressive language means for the desired output. They must be familiarized with the conventions of a kind of writing that is relevant to a given situation.

The other point is that writing is not just achieved by the mechanical means alone.Not only do learners need grammar knowledge, but they also need to find the most effective way for communicating ideas. Without this skill, it might be difficult for the ESP student to exercise their thinking in the target language (cf. Peyton, 1993; Tran, 1997). For the grammar and the vocabulary outlined in the course to benefit writing, there needs to be a great deal of reinforcement from outside the classroom (cf. Bello, 1997).

In summing up, writing tasks included in ESP1 and ESP2 are both suitable and relevant. However, progress with writing in English where it is used as a foreign language requires more creativity than the course offers.

\subsection{Perceptions, Experiences, and Opinions about Writing Tasks}

Data collection process for this objective took ten days during which the researcher set aside one day for each student. Depending on the availability of the student, a session ranging from 45 minutes to 1 hour was sufficient to have them address the issues raised. An interview guideline used to gather information from the informants was divided into two subsections. Section A primarily aimed to make the informant relaxed enough to answer specific questions on writing. The guideline only served as a point of reference as the interview progressed. 


\section{Section A}

This section included a set of foundational questions addressing issues like the proficiency level in English and the language background. Its aim was to explore background experiences the informants have with English. With only slight variation in wording and order of question presentation, informants responded as indicated in the discussion that follows.

The informants were unanimous that they were taught both Arabic and English in response to the question "which language(s) were you taught in school before university?" They indicated they learnt English as a subject but that their schools used Arabic as a medium of instruction for all other subjects. This means two important things: one; that it is only possible they arrived in the university with fair knowledge of English, and two; that they were at about the same level of proficiency in English at entry point (with minor variations).

Informants said they learnt all the courses they took each academic year in Arabic except the English courses. Note that several courses in our university feature a component of English in their design owing to their technical nature. Necessary knowledge of English is usually only functional. But it should be emphasized that the context in which or students learn is dominated by Arabic, in and out of class.

When asked to give their honest opinion in response to the question "in which language do you enjoy learning?" Only 2 out of 10 said they enjoyed learning in English; the rest indicated Arabic. The majority favor Arabic because they are native speakers of it and therefore more at home learning in it.

Their self-reported ability to speak Arabic very well was excellent for all cases. When it came to English, there were varying responses; 2 said "very good", 1 said "good", 4 said "moderate", while the rest 3 said "not good".

Without going into investigating the details of how the informants used English with whom, where and for what purpose, it can be surmised from the responses that the majority of the students in the ESP class had only a fair background in English. In fact, the researcher could tell from conversations during the interview that more than half the informants only had smattering knowledge of the language. About 3 could speak English quite well, though. Whatever the case may be, readiness of these informants for the writing task must then be understood in terms of their readiness as reported in the foregoing results.

\section{Section $B$}

Each informant was led through another set of questions related to writing. Like with the previous section, each interview session was conversation-like, meaning there were variations in wording as well as order of the questions. The questions mainly sought opinions, perceptions, abilities and views about writing in English. As can be seen from the tables, the actual interview questions were not presented; rather, I rephrased the responses for presentation purposes. Each response arising from a question occurs in the variable column. The second column shows frequency of occurrence for each response.

Informants expressed their opinions on issues related to writing in English.

Table 1. Opinions about writing in English

\begin{tabular}{ll}
\hline Variable & Frequency \\
\hline I like to write in English & 3 \\
I practice writing in English & 5 \\
I cannot write in English because my English is not very good & 2 \\
I do not write in English (because I do not know how to write in it) & 2 \\
I do not enjoy writing in English because it is difficult for me & 4 \\
I do not practice writing in English because it is not important for my studies & 3
\end{tabular}

A total of 10 students participated in the interview. This means responses shown in the frequency column in Table 1 exhibit overlap across cases. This is because the questions themselves were not mutually exclusive. Two (2) informants said they could not write in English, 2 said they did not, 4 said they did not enjoy writing in English while 3 confessed they did not practice writing. Nevertheless, 3 informants liked to write in English and 5 said they practiced writing in it.

We can conclude many things from these responses, but it is highly likely that those who said they could not write in English meant they were shy to do so (otherwise they could). Similarly, informants who said they "did not" write in 
English were probably referring to their imperfect writing skills rather than their inability to write in English. Three (3) or so informants in this category could very possibly be among the 5 who practiced English. Those who said they did not enjoy writing in English appeared to recognize the sacrifice involved. So, I wouldn't say they gave up at the end of the course. However, the 2 who said they did not practice writing in English because it was not important for their studies are cause for worry to the ESP instructor.

In general, an outright supportive opinion about writing in English among the interviewed ESP students is as low as fair. Because of that, we can say the students have limited chance to reinforce the grammar and vocabulary they learn in class as observed above in section 3.1.1. In any case, there is evidence from section A that the majority of the students joined university without a strong background in the English language skills. It therefore does not help matters that the ESP course itself integrates listening, speaking, reading and writing.

Course orientation of the ESP course book leads the teacher to teach how to write together with what to write, which may be confusing to some students. From the product perspective, the student is taught mechanics of writing involving punctuation, capitalization, spelling, and sentence structure. Yet they exercise their writing skills, not in English, but in Arabic. This study is therefore very much in agreement with Al-Khasawneh (2010) who observes that Arab learners of English still have many problems when writing in English because it is a new experience for them.

Informants were asked another set of questions meant to prod them further on beliefs they expressed about writing in English. They had the following to say with respect to perceptions about writing in English.

Table 2. Perceptions about writing in English

\begin{tabular}{ll}
\hline Variable & Frequency \\
\hline It is important to write in English & 10 \\
I can write in English & 8 \\
I always need help when I write in English & 4 \\
I am not a good writer in English & 4 \\
I do not feel comfortable when asked to write in English & 3 \\
English spelling is difficult & 5 \\
I need more classes to be able to write in English & 5
\end{tabular}

Regardless of the low outright supportive opinion about writing in English reported in Table 1, all informants admitted that it was important to write in English (see Table 2). Perhaps due to that, nearly all respondents implied they needed help ( 8 said they could write, 4 said they needed help, 4 said they were not good writers in English, 3 weren't comfortable writing, 5 cited spelling problem while 5 said more classes would be helpful). So, unlike opinions, perceptions are quite supportive of acquisition of writing skills in English among the informants. However, when prodded about actual writing abilities in English, rather ambivalent results followed as we can see from Table 3.

Table 3. Specific Writing abilities in English

\begin{tabular}{ll}
\hline Variable & Frequency \\
\hline I can write a report in English & 4 \\
I can write a job description in English & 4 \\
I can write a review of weather report in English & 3 \\
I can write directions in English & 4 \\
I can write travel plans in English & 5 \\
I can write narrative of an incident in English & 3 \\
I can write a report defending my employer in English & 2 \\
I can take notes during a drill I English & 2 \\
I can write my diary in English & 5 \\
I can describe a scene in English & 4 \\
I can argue in English & 3 \\
I can reason in English & 3 \\
\hline
\end{tabular}


Clearly, only 5 out of 10 informants said they could undertake less demanding tasks like writing their diary or travel plans in English. There was unease in the rest of the cases. For instance, only 3 informants felt they could engage in writing tasks that involved reflection such as reviewing weather, narrating an incident, arguing or reasoning. It is therefore not surprising that 2 informants reported ability in the case of a more thought intensive task like defending the employer or a spontaneous one like taking notes during a drill.

Table 3 tells us how not ready the sample of ESP informants were in writing abilities that require critical thinking which is defined by Chane (1986) as ability to analyse facts, generate and organize ideas, defend opinions, make comparisons, draw inferences, evaluate arguments and solve problems. As a consequence we have a case where informants have better perceptions (see Table 2) than self-reported abilities (see Table 3). Answer to what causes this ambivalence takes us to the third objective of this paper.

\subsection{Relating Writing Tasks to Critical Thinking Skills}

The third objective wraps up the focus of this paper by interrogating the match between writing tasks given to the ESP students of Aqaba College and the skills characterized in section 2.2. as critical thinking skills.

Following Delphi conceptualization (Quitadamo and Kurtz, 2007), critical thinking includes analysis, inference and evaluation. Analysis involves breaking a concept or idea into component pieces to understand their inherent relationships. Inference is used to reconcile what is known with what is unknown while evaluation considers available evidence with a view to arriving at reasonable conclusions.

The Survey of ESP1 and ESP2 Writing Tasks presented above in section 4.1.1 reveals that the informants are taught Descriptive essays, Instructions, Various reports (of weather, incidents, changes, trends etc.), Travel plans, Safety notices, Job descriptions, Formal letters, Reviews of weather reports, Directions, Notes, and Argumentative essays (involving cause and effect) as specific writing tasks. Let us examine these tasks closely to see how much analysis, inference and evaluation they contain.

Units like Forms of writing, Descriptive essays, Instructions, Travel plans, Safety notices, Job descriptions, Formal letters, and Directions do not require critical thinking. As noted by Resnick (1987) and Marzano (1991), writing only becomes an active process allowing improved thought when it provides a context for interpretation to enable higher order of thinking. By means of these principles, writing is an active process allowing improved thought. It provides a context for interpretation and enables higher order of thinking (Resnick, 1987; Marzano, 1991). Undergraduates are expected to master critical thinking skills during their college education, regardless of discipline (Greenlaw and DeLoach 2003).

Apart from argumentative essays that involve cause and effect or review of weather reports, none of the writing tasks presented to ESP students reflects principles that demonstrate critical thinking outlined in Northedge (2005). For writing to benefit thinking, an individual should be able to make their ideas explicit and to evaluate and choose tools necessary for an effective discourse (Quitadamo and Kurtz, 2007). This is clearly not the case with the ESP program.

\section{Conclusion}

This paper has demonstrated that there is low correspondence if any between writing tasks contained in the ESP programme and critical thinking skills. Since writing and thinking should be interdependent to benefit learning, I have shown that writing tasks featured in the programme pursue more mechanical writing than thinking. I reiterate that writing can boost thinking, but only if a careful choice is made of writing tasks including forms of writing that require cognition. Foreign language students like Maritime ESP students of Aqaba College could only internalize and therefore able to apply higher level writing tasks demanding evaluation, inference, comparison or examination if their listening, speaking, reading and writing skills in English receive more attention before they come to university.

\section{References}

Abbad, A. (1988). An Analysis of Communicative Competence Features in English Language texts in Yemen Arab Republic. PhD Dissertation, University of Illinoisat Urbana-Champaign.

Ackerman J. M. (1993). The promise of writing to learn. Writ. Commun. 10(3), 334-370.https://doi.org/10.1177/0741088393010003002

Al-Khasawneh, M. S. F. (2010). Writing for Academic Purposes: Problems Faced by Arab Postgraduate Students of the College of Business, UUM. ESP World, Issue 2(28), Volume 9.

Bello, T. (1997, March). Writing topics for adult ESL students. Paper presented at the 31st Annual Teachers of English to Speakers of Other Languages Convention, Orlando, FL. 
Bloom, B. (1956). A taxonomy of educational objectives. Handbook 1: Cognitive domain. New York: McKay.

Chane, P. (1986). Thinking in the Classroom: A Survey of Programs. New York: Teachers College, Columbia University. Retrieved on 29th November 2016 from http://edpsycinteractive.org/topics/cogsys/critthnk.html

Duron, R. Limback, B. and Waugh, W. (2006). Critical Thinking Framework for any Discipline. International Journal of Teaching and Learning in Higher Education. 17(2), 160-166.

Ennis R. H. (1985). A logical basis for measuring critical thinking skills. Educ. Leadership. 43(2), 44-48.

Fisher, A. (2001). Critical Thinking: An Introduction. Cape Town: C.U.P

Greenlaw, S. A. \& DeLoach, S. B. (2003). Teaching Critical Thinking with Electronic Discussion. The Journal of Economic Education, 34(1), (Winter), 36-52. https://doi.org/10.1080/00220480309595199

Hyland, K. (2003). Genre-based pedagogies: A social response to process. Journal ofSecond Language Writing, 12, 17-29.

Klein, P. D. (2004). Constructing scientific explanations through writing. Instr. Sci., 32(3), 191-231.https://doi.org/10.1023/B:TRUC.0000024189.74263.bd

Marzano R. J. (1991). Fostering thinking across the curriculum through knowledge restructuring. J. Reading, 34(7), $518-525$.

Northedge, A. (2005). The Good Study Guide. Open University: Buckingham. In "Developing Critical Thinking"

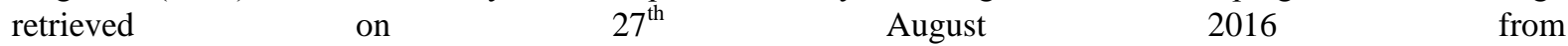
fromhttp://www.emeraldgrouppublishing.com/learning/study_skills/skills/critical_thinking.htm

Paul, Richard et al. (1989). Critical Thinking Handbook. Foundation for Critical Thinking.

Peyton, J.K. (1993). Dialogue journals: Interactive writing to develop language and literacy. ERIC Digest. Washington, DC: National Center for ESL Literacy Education. (EDRS No. ED 354 789).

Quitadamo I. J, Kurtz M. J. (2007). Learning to improve: using writing to increase critical thinking performance in general education biology. CBE Life Sci Educ. Summer, 6(2), 140-54.

Rashid, R.A. \& Hashim, R.A., (2008). The Relationship between Critical Thinking and Language Proficiency of Malaysian Undergraduates. Proceedings of the EDU-COM 2008 International Conference. Sustainability in Higher Education: Directions for Change, Edith Cowan University, Perth Western Australia, 19-21 November 2008.

Resnick L. B. (1987). Education and Learning to Think. Washington DC: National Academy Press.

Rivard L. P. (1994). A review of writing to learn in science: implications for practice and research. J. Res. Sci. Teach.,31(9), 969-983.https://doi.org/10.1002/tea.3660310910

Scardamalia, M., \& Bereiter, C. (1987). Written composition. In M. Wittrock (Ed.), Handbook on research on teaching, 3, 778-803). New York: MacMillan.

Sumner, W. G. (1906). Folkways: A study of the sociological importance of usages, manners, customs, mores, and morals. Boston, MA: Ginn and Company.

Tran, H. (1997, March). Becoming a writer. Paper presented at the 31st Annual Teachers of English to Speakers of Other Languages Convention, Orlando, FL.

Tribble, C. (1996). Writing. Oxford University Press

Wade, C. (1995). Using Writing to Develop and Assess Critical Thinking. Teaching of Psychology. 22(1), 24-2. https://doi.org/10.1207/s15328023top2201_8

Winbow, A. (2002). The importance of effective communication. International Seminar on Maritime English.

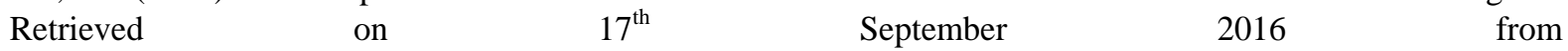
http://www.imo.org/includes/blastDataOnly.asp/data_id=18000/InternationalSeminar.pdf.

Zughoul, M., \& Taminian, L. (1984). The linguistic attitude of Arab University students: Factorial structure and intervening variables. The International Journal of the sociology of Language, (50), 28-45.https://doi.org/10.1515/ijsl.1984.50.155 